\title{
UNDERSTANDING CAMBODIAN TOURISM DEVELOPMENT THROUGH CONTEXTUAL EDUCATION
}

\author{
ARIANE PORTEGIES, THEO DE HAAN, RAMI ISAAC, and LUCETTE ROOVERS \\ International Tourism Management and Consultancy, NHTV Breda University of Applied Sciences, \\ Breda, The Netherlands
}

\begin{abstract}
Within a field that has prioritized ideas of a global tourism industry impacting on a local environment, less attention has been given to regional, cultural, and geographic differences and parallels. A problematic concern in the study of tourism was perhaps the lack of contextualization and the integration of the units of analysis (e.g., tourist destinations) to the larger regional structures and societal processes. We wish to take up the challenge to further disturb the foundations of the field and, more importantly, to participate in the advancement of a more pluralist discourse. A central component in this article is a 5-day study visit in Siem Reap, Cambodia as part of an Asia-based fieldwork of bachelor students in tourism development at NHTV University of Applied Sciences in Breda, The Netherlands. This study visit serves as an illustration of the contextual education approach developed in the tourism course and facilitated by the international classroom setting. This fieldwork's philosophy and the inspirational encounters made possible by it is an attempt to address the challenges posed by the study of the dynamism and changing character of destinations. To conclude we will bring forward selected student experiences as well as dimensions of Cambodian history and society that have enriched our understanding of Siem Reap as a destination. This experience will fuel a discussion on knowledge production in tourism and on the added value of this contextual education approach. The repeated opportunity for our students to meet, think, and reflect on what they were confronted with created a possibility to uncover more than would have been possible via standard research methods using surveys and interviews.
\end{abstract}

Key words: Contextual education; Knowledge production in tourism; Tourism developments in Siem Reap; Cambodia; Asian perspectives; ITMC student encounters

\section{Introduction}

The aim of this article is to explore and discuss contextual education as a best practice for knowledge production in the field of tourism. By way of an illustration of this approach-a 5-day stay in Siem Reap, Cambodia as part of an Asia based fieldwork in the context of the International Tourism Management and Consultancy (ITMC) Bachelor course at NHTV University of Applied Sciences

Address correspondence to Ariane Portegies, M.Sc., Senior Lecturer International Tourism Management \& Consultancy, NHTV Breda University of Applied Sciences, P.O. Box 3917, 4800DX Breda, Netherlands. Tel: 0031 (0)76-5332371; Fax: 0031 (0)76 5302295; E-mail: Portegies.a@nhtv.nl 
in Breda, The Netherlands - the concept of contextual education will be further defined, as strengthened and facilitated by the international classroom setting (Portegies, de Haan, \& Platenkamp, 2009). ITMC is a 4-year European-based program with an international scope, welcoming students from a range of countries worldwide. A 3-week destination fieldwork where all second year students learn and stay on location in Asia forms a prominent part of the study program. A contextual educational approach is strongly reflected in the fieldwork assignments and activities. Siem Reap, Cambodia, and Koh Samui, Thailand were the areas defined for the 2009 portion of this ITMC fieldwork. This article will pay specific attention to the 5-day visit stay in Siem Reap at the start of the fieldwork program, including selected reflections of students on their contextual learning experience in Cambodia. This experience will fuel a discussion on knowledge in tourism and on the added value of this approach.

First the article will clarify the concept of contextual education, and the special role of the "international classroom" space (Lengkeek \& Platenkamp, 2004). Second, after due attention to the situation of tourism development in Cambodia, we will argue for the need of Cambodian (and Asian) perspectives, without which Cambodia as a destination remains a Western destination for Western markets. Indeed, within a field that has prioritized ideas of a global tourism industry impacting on a local environment, less attention has been given to regional, cultural, and geographic differences and parallels (Winter, 2007a). Elaborating on this "Anglo-Western centrism" Winter (2009) further posits that the critical voices of Alneng (2002), Edensor (1998), and Williams, Hall, and Lew (2004) and the various studies conducted on domestic and regional tourism in regions outside Europe and North America have yet to disturb the ethnocentric foundations of the field, which emerge from the widely held assumption that tourists come from the West and that "the modern tourism industry" is essentially Western in its origins. We wish to take up the challenge to further disturb the foundations of the field and, more importantly to participate in the advancement of a more pluralist discourse.

A central component in this article will be the 5-day program itself, its philosophy, and the inspirational encounters made possible by it: it is an an- swer, an attempt, to the challenges posed by the study of the dynamism and changing character of destinations. To conclude we will bring forward selected student experiences as well as dimensions of Cambodian history and society that have enriched our understanding of Siem Reap as a destination. These discoveries were facilitated by the contextual educational approach.

Findings on destination developments in Siem Reap and Cambodia elaborated on in this article are based on authors' field research and interviews carried out during a total of 5 visits done between June 2007 and April 2009. In addition to this research, authors in the field were namely inspired by the works of Winter (2007a, 2007b, 2009) and van de Put and Eisenbruch (2002). We appreciated the approach and recognized the far-reaching empathic capacities in their studies on heritage in Angkor and healthcare in Cambodia, where historical and societal accounts play major parts.

\section{Contextual Education and the International Classroom}

Destinations are dynamic and ever changing spaces continuously performed and shaped by the visitors and inhabitants. Clearly, a destination is more than a sum of empirical facts related to tourism. It also includes the way people live and work, currently and in the past. Understanding a destination can only be done in that context. Hall (2005) pointed out that the problematic issue in the study of tourism was perhaps the lack of contextualization and the integration of the units of analysis (e.g., tourist destinations) to the larger regional structures and societal processes. In his various publications on tourism of Asian origin, Winter (2007a) and Winter, Teo, and Change (2009) also draws attention to this and argues that in its current form the field of tourism studies is institutionally and intellectually ill-equipped to understand and interpret the new era we are now entering. He suggests that the core-periphery dynamics that characterize the field today should give way to cultural and political pluralism (Winter, 2009).

In order to have students discover the changes and dynamics of tourism destinations, a contextual approach has been developed at NHTV (Platenkamp, 2006; Portegies, de Haan, \& Platenkamp, 
2009). Contextual education starts from the complexity of our network-society (Appadurai, 1996; Castells, 2000; Hannerz, 1993). In a contextual approach students are encouraged to start by-as much as possible-leaving their frameworks behind. Simultaneously to having preconceptions and stereotypes about tourism development, these students are very open to new information and new situations. The contextual approach departs from the idea that many relevant insights in the study object - for example a tourism destination - may be found in unwritten or implicit types of information. A master plan or a regional development plan, a destination value chain report, a marketing plan for a hotel, figures about beds, overnight stays, and arrivals provide students with the illusion that they have all relevant insights in a destination. A contextual approach makes this type of information more secondary, more subordinate, while paying attention to what is happening "on the street" becomes more relevant: how people sell souvenirs and develop other forms of entrepreneurship, how people spend their time, learning, working, caring for their families, but also the variety of tourists walking around at different times of the day and in different areas of the destination.

This contextual approach has grown gradually within the limits of a tourism practice in higher education at NHTV Breda University of Applied Sciences (in the Netherlands). At its start, it was instrumentalist in outline, and step by step in an "incremental" way, gradually, an educational practice developed that can be characterized by a "contextual practice" of higher education. Earlier work provides a history of this practice and a critical reflection on the added value of this approach. (Portegies, de Haan, \& Platenkamp, 2009).

\section{International Classroom and Self-Reflexivity}

The practice of the International Classroom (IC) (Lengkeek \& Platenkamp, 2004) mixes with tourism practice in international destinations in an inspirational manner and with mutual respect. Students from a variety of backgrounds, and most of whom do not originate from the destination visited, bring within them their own contexts, their own learning resources, valuable for themselves, for their fellow students, and also for the teaching staff.
The IC is composed of hybrids, footloose, sedentary, tourists, indigenous, strangers, migrants, friends, and family; it is a cross-section of our networksociety and in which networks interfere (Appadurai, 1996; Castells, 2000; Hannerz, 1993). The awareness of students of their own contexts increases significantly while living and researching in another context. This "self-reflexive" perspective is a necessary step in the opening up to new situations and for the development of new insights (Platenkamp, 2006). In addition to actively using this phenomenon of "being overwhelmed," the contextual approach also encourages students to open up to it further. Students' observations, their encounters with the people they meet unexpectedly or without a study purpose, but also their diaries, emails, and text messages they send home, these all become part of the field research. Applying the international classroom concept thus expresses the intention and practices in ITMC to recognize, bring to the fore, and actively put to work the plurality that is reality in most classrooms - and tourism destinations - today. It is a space where discussions take place between perspectives. These discussions are impregnated with hidden moral and existential questions (Isaac, Platenkamp, \& Portegies, 2009). These types of questions are rarely dealt with in education, business, and academic contexts. The identification and introduction of these questions in professional analyses is thought to enhance understanding and scientific reflection.

\section{Research Design and Fieldwork Design}

Mid-March 2009, 114 second-year NHTV tourism students arrived in Siem Reap, Cambodia. This heterogeneous group of students aged between 19 and 23, from Europe, Latin America, and Asia had different perspectives in observing developments in society and in tourism, because of their different backgrounds. The IC concept requires these perspectives to be made explicit by way of self-reflexive assignments and student discussions, in order to identify and further develop meaningful insights. The arrival of this group in Siem Reap symbolized for many their "arrival in Asia" experienced from their heterogeneous perspectives. Before moving on to Bangkok and Koh Samui by coach and ferry, a 5-day program in Siem Reap was to "set the 
scene" for the rest of their 3-week field work. A conscious choice was made for a slow approach, with room for acclimatization and own explorations.

Prior to the details of the program in Siem Reap specifically (Fig. 1), let us briefly situate it in the broader context of ITMC's yearly fieldwork philosophy. Understanding tourism and the development of destinations is a focal point of the International Tourism Management and Consultancy Bachelor degree (ITMC) at the NHTV Breda University of Applied Sciences. For 12 years now, the "destination fieldwork" has been a prominent component of the ITMC program is designed to create and make use of complex cultural environments as a learning environment for students. Bali, Phuket, and Koh Samui were prime locations for this work. In 2007, ITMC moved further into Asia by introducing the Central Coast area of Vietnam and Siem Reap in Cambodia as areas for student research.

In order to determine how students engaged with the context in Siem Reap and with self-reflexivity processes, a series of classroom sessions were organized on the last day of the program. The sessions started with broader observations and personal experiences of students, and then in a second instance they developed on more specific observations on characteristics of tourism development. The encounters students had were a mixture of organized encounters with stakeholders and professionals in tourism on one hand, and "accidental" encounters with local people, shopkeepers, hawkers, children, and tuk tuk drivers on the other. Incompany visits and professionals were selected based on their involvement and commitment to Cambodia and to Khmer culture. Both the philosophies and the operational activities of these organizations, Hotel de la Paix, the Art Venues, FCC Hotel, Sala Bai Hotel School, etc. (for detailed descriptions see Fig. 1) and reflect the embodiment of Cambodia's historical, social, and economic contexts.

Records were made of the four reflexive classroom sessions on day 5: each session was loosely guided by a moderator, and two staff members took notes to be compared and merged into two reports, one for each student shift. In addition to these discussion reports, students had to produce a logbook per fieldwork team and an individual story of an encounter with a local, or hybrid, footloose, sedentary, tourist, indigenous, stranger, migrant, or inhabitant of Siem Reap.

\section{The Need for Asian and Cambodian Perspectives}

When applying a contextual approach it is also necessary to include the broader Asian aspects of the Cambodian circumstances of tourism development in Siem Reap. This leads to insights in what is happening in Cambodia and Asia's economical, political, and cultural environments, which are relevant in the understanding of (potential) tourism developments. The enriching meetings and discussions with experts, writers, and practitioners in tourism development (for a list of interviewees is show in Table 1) informed the design of the fieldwork program. In turn, the experience of the fieldwork, seeing and hearing about students' engagements and experiences helped explicitate aspects of contemporary Cambodian society that deserve more ample attention in a more pluralist discourse. This mutual engagement between students' discoveries and understanding of tourism development has lead to a call for more and more prominent Asian and Cambodian perspectives which is argued in the following part.

\section{Tourism Development in Cambodia and Siem Reap}

Although the main built heritage attractions in Cambodia number over in total 100 sites (Phuong, 2003) in terms of visitor numbers the attraction sector is dominated by Angkor Wat near Siem Reap, which is one of the most impressive World Heritage Sites. Already under the French Protectorate rule Angkor Wat came into fashion as the exotic tourist attraction of "Indochine," a role that, with ups and downs due to political circumstances, has since been taken in by the ancient former Khmer capital.

Focusing on Angkor the first Lonely Planet on Cambodia was published in 1992. Its descriptions of landmines and war-torn cities and recommended "not to miss highlights" like jungle-hidden ruins, had a significant impact on the physical development of the emerging destinations Siem Reap and Angkor (Winter, 2007b). In the 1990s, however, Cambodia's tourism industry was undeveloped compared to Malaysia, Thailand, and Vietnam. A 
registered amount of 8,000 tickets were bought for Angkor by tourists in 1994, rising to less than 41,000 in 1998, then to 750,000 in 2003 (Winter, 2007b, 2009). Also the opening of Siem Reap airport in 1998 for international arrivals took care for the take off of Siem Reap and Angkor as a tourism product available to the world tourist market. Located in the west of the country, the beginning of direct flights has helped to increase visitor numbers directly to Siem Reap and has reduced transit traffic that used to be routed through the capital Phnom Penh (Lennon, 2009).

As a country Cambodia has shown significant growth in inbound tourism until 2009. The growing number of tourist arrivals in Cambodia over the years is a result of several reasons. Firstly, the number of people traveling in general is increasing. Secondly, the more popular destinations in the region have been visited (e.g., Thailand, Malaysia, Indonesia) and there are more options for other destinations. Thirdly, the northeast Asian outbound market is growing rapidly caused by regional economic growth, rising disposable incomes, and decreasing travel costs, and finally, as a result of the promotional efforts regarding these regional markets (Winter, 2007a).

The total number of tourists visiting Cambodia in 2008 increased by $5.48 \%$; this is translated into 2.12 million tourists (Ministry of Tourism, 2009). Direct employment in travel and tourism for 2008 was estimated at $1,102,000(15.4 \%$ of the total workforce or 1 in every 6.5 jobs) (World Travel and Tourism Council [WTTC], 2008). This is quite high compared to the average of $8.5 \%$ related jobs in tourism for the entire South East Asian region. However, the growth of the number of tourist arrivals in 2008 was rather disappointing in comparison to 2007 's $18.5 \%$ (Ministry of Tourism, 2009). The main reasons for this decrease are the political crisis in Thailand, the conflict between Cambodia and Thailand over the Preah Vihear temple, and the global financial crisis. Up until the 2008 economic crisis, the industry leaders in Siem Reap were dealing with a lack of rooms and lack of skilled staff as main challenges. The consequences of the crisis were not clear yet when our students visited the city in March 2009. However, the impact of the closing of Bangkok airport and downturn of tourism development in Thailand at the end of 2008 had an im- mediate visible consequence for visitor numbers to Siem Reap. At this moment, there is no more talk of room scarcity and a labor surplus is starting to be perceived. Hospitality professionals and training institutes recognize new times are ahead (interviews field research, 2008, 2009).

It is important to realize that visitor numbers to Cambodia and Siem Reap are increasingly growing by the many developing Asian markets. This growth in intraregional tourism, initially led by Japan, has continued to gain impetus with ever-increasing arrivals from Taiwan, Korea, and China (Ministry of Tourism 2000, 2003). By 2003, nearly $60 \%$ of the 701,000 tourists entering Cambodia originated from Asia, with around two thirds of that figure accounted for by countries located in the northeast of the region (Ministry of Tourism, 2003). The Ministry of Tourism (2003) states, the fastest growth from 2002 came from Korea, Malaysia, and Thailand. The less impressive, but still notable, increase from China and Taiwan ensured Cambodia and Angkor in particular were entering a new era of tourism. As in 2008, Korea is the key generating market in the top 10 arrivals to Cambodia. Korea's market share is of nearly $13 \%$ in 2008, followed by Vietnam with a share of $10 \%$, and Japan on the third place with $8 \%$. The remarkable increase of Vietnamese travelers to Cambodia from 2007 to 2008 was $67 \%$, while the number of Korean travelers declined by $19 \%$ in the same year (Ministry of Tourism, 2008).

During the 1990s, Siem Reap witnessed a rapid increase in Korean, Japanese, and Chinese expatriates operating in its tourism business. Another important major economic development of the country is that the town is now home to a very important proportion of estimated 30,000 mainland Chinese living in Cambodia (Beech, 2005). Since the late 1990s, Siem Reap has also witnessed a tremendously rapid growth in the number of businesses catering to Asian tourist and markets, particularly the Chinese, Korean, Japanese, and Taiwanese markets (Winter, 2007a). As a result, a high level of integration (vertical as well as horizontal) had developed between several travel agents, restaurants, souvenir shops, and hotels, all targeting markets from Northeast Asia (interview with N. Henderson in 2008 and N. Downing in 2009). Much of the investment in these products and facilities has come from outside Cambodia. 


\title{
Day 1
}

After a discovery of Singapore during the day the students arrived in Siem Reap late afternoon.

Day 2

In the morning students had time for acclimatisation. Most students made use of the opportunity to discover the surroundings on their own, some rented bikes, other explored by walking around or hiring tuk tuks. In the afternoon 5 different actors in Siem Reap's tourism scene agreed to welcome a group of 10 to 20 students for a first encounter in Cambodia. The Sala Bai Hotel School, Sam Veasna Centre for Wildlife Conservation, The Artisans D'Angkor Cambodian Arts and Crafts, FCC Angkor design hotel, and a selection of Siem Reap's Art Venues namely the Hotel de la Paix's Art Lounge, John Mc Dermott's photo gallery and Carnets d'Asie.

\section{Sala Bai Hotel School}

Created in 2002 by the French NGO "Agir Pour Le Cambodge", Sala Baï is a free hotel school based in Siem Reap, Cambodia. Each year, the school, trains 100 young disadvantaged Cambodians to the four main professions of the hospitality industry: restaurant waiter/waitress, cook, receptionist \& housekeeping attendants. During the 12-month training, the school covers all the training fees (lessons, school supplies, books, uniforms), and daily expenses (accommodations, food, bicycle, insurance and medical expenses) for the students. (salabai.com)

Students enjoyed lunch, cooked and served by the Hotel school students and got an introduction to Sala Bai and their objectives by Anne Rolland, Director of Sala Bai. In classrooms a group of about 4 NHTV students and 6 Sala Bai students, accompanied by a Hotel school lecturer, had the opportunity to meet. Daily student life of NHTV students was presented and supported by pictures.

\section{Sam Veasna Centre for Wildlife Conservation}

Sam Veasna Centre for Wildlife Conservation (SVC) is a registered Cambodian non-profit, non-governmental organization. The aim of SVC is to serve as a focal point for conservation initiatives in north-western Cambodia.

The Center was established in 2003 in memory of Sam Veasna, a pioneering Cambodian conservationist whose work led to the rediscovery and protection of the highly endangered bird, the Bengal Florican.

Veasna dreamt of building a centre to promote the conservation of wildlife. However, he succumbed to cerebral malaria at the age of 33 after contracting it during fieldwork in December 1999. (samveasna.org)

While enjoying lunch at the Sam Veasna centre the mission of the centre was explained by its coordinator Nick Butler. To get a better insight in the ecotourism business in practice, a SVC guide was willing to share his perspective with the students.

\begin{abstract}
Artisans d'Angkor
Artisans d'Angkor was established to provide sustainable and fair development for arts and crafts in Siem Reap province. The enterprise is offering young artisans a job on-site or in its rural workshops in Siem Reap surroundings. Since its creation, Artisans d'Angkor has engaged itself by being a poineer in social policy in the country, guaranteeing levels of pay and social and medical welfare. The enterprise gives artisans fulfilling and stable working conditions and provides them with a vocation so they can express their talent and continue to develop their skills. The enterprise has renewed interest in the authenticity and value of the strong Khmer identity. Artisans d'Angkor has developed its own training programme and hired young apprentice trained by the Chantier-Ecoles de Formation Professionnelle (CEFP). Initially the CEFP was created in 1992 to respond to a young population in need with very little education. Artisans d'Angkor is now completely self-financed and creates jobs in rural areas. Nowadays, it has created over 1000 jobs (which 713 are artisans) and has established 13 workshops in 12 villages in Siem Reap province. (heritagewatchinternational.org)
\end{abstract}

The objectives, goals as well as the marketing approach of Artisans d'Angkor was introduced to the students. Afterwards, in smaller groups, the site of Artisans with all its training elements was shown to the students in a guided tour. Being in the company of a guide gave the opportunity for asking questions to both guides and trainees.

\section{FCC Angkor hotel}

Renovated from the old French Governor's mansion, art deco embraces chic hotel, creating an atmosphere of refined luxury and casual elegance. (http://www.fcccambodia.com). More than a club for expats, the FCC houses a speciality bookshop on Khmer/Cambodian subjects and two remarkable galleries. One features the photography of Jonhn McDermott, a minor celebrity in these parts know for his great black and while images. The other is a Jerry Swattfield's art gallery, a collection of truly eclectic stuff; ghoulish comic books and Francis Bacon-esque paintings, as well as photography exhibit on the persecuted Hmong people of Laso. (lifestyleandtravel.org)

During a presentation and guided hotel tour by FCC's GM Benoit Jancloes and staff, the students were introduced to the different management and marketing aspects of the hotel as well as the perspectives of the Cambodian and international staff on life and work in Cambodia.

As suggested in the 'Art Venues' publication produced jointly by a collaboration of artists and galleries in Siem Reap, the students made a trip along 3 art galleries. An insight was given in the artistic tradition of Cambodia, the exhibitions and the cooperation of the contemporary art venues. Don Protasio, Curator of the Arts Lounge in Siem Reap's modern Hotel de la Paix referring to the vivid present day Khmer arts wave: "creativity is not what you have, but what you do with what you have" explained the full focus on Khmer artists in order to create international output possibilities for modern national Khmer culture expressions. 


\section{Hotel de la Paix - Arts Lounge}

The Arts Lounge central on the ground floor of the Hotel de la Paix is a living space dedicated to thef Cambodia's rich cultural heritage. It represents a commitment to the country's dynamic present and offers a laboratory for its creative future. The thought provoking exhibits pay homage to the Khmer heritage and to the revival of a nation's arts, culture and people. The Arts Lounge showcases to all the spirit of Cambodian culture in its various forms - both past \& present, traditional and contemporary.

Along with supporting Cambodian artists and showcasing original works, The Arts Lounge promotes a borderless exchange of ideas and encourages expression of thought from both international and local sources. Visitors from near and far will take with them new ideas, a deeper understanding of Khmer culture and an appreciation of Khmer heritage with the global context.(hoteldelapaixangkor.com)

\section{John Mc Dermott's photo gallery}

There is an amazing arts scene in Siem Reap. Art Venues, a free brochure available in upmarket hotels, lists 10 art galleries that are all within walking distance around the quaint town. McDermott Gallery, Old Market houses an amazing mix of work by local and international photographers. John McDermott, an American photographer who has been living in Siem Reap for almost 10 years, owns the galler. (johnmcdermott.com)

\section{Day 3}

A day to discover the Angkor complex in smaller groups with 'personalised' guidance to allow for more profound encounters and experiences. The guides of the Khmer Angkor Tour Guide Association were prepared to go beyond the 'normal' tour along the Ankor Wat complex. They were prepared to answer, and students were prepared to ask questions about the role of Angkor tourism in the daily life of the guides. The 'guided' student groups -being facilitated with their own vans- had the opportunity to visit areas outside Siem Reap such as the home village of the guides, other rural areas or a 'must-see' floating village.

\section{Day 4}

Lecture in the Angkor Century Resorts and Spa by its General Manager Raymond Pereira. He introduced the students into the Asian ways of life and work and on the challenge of running a hotel business in Cambodia. An Asian perspective "we (Asians) work on liking what we do, rather than doing what we like" aroused vivid discussions. The program was continued at the pagoda Wat Damnak, giving room to the Life and Hope Association (LHA).

\section{Life and Hope Association}

LHA is a Cambodian non-profit, non-governmental and non-political organization, established in 2005, by the Young Monks of Wat Damnak, Young Khmer Youths and generous friends, who saw the urgent needs of the Orphans and Vulnerable Children, who are living with miserable lives in the various communities. LHA works with several active villages in and surrounding the Siem Reap and Bakong District, with aim to alleviate poverty/difficulty of poor families, especially Cambodian Children by supporting them with basic needs such as foods, clothing, school supplies, health services, education, accommodation etc. (http://www.watdamnak.org/lha/)

Shinta Mani Hotel is one of the funding partners for LHA, being our guide for today they brought us to the pagoda where the students see the community-based activities and get an insight in LHA's activities.

\section{Shinta Mani Hotel \& Institute of Hospitality}

Shinta Mani, which is derived from Sanskrit, meaning "The gem that provides everything one desires" is a perfect description for this intimate friendly 18 rooms boutique hotel and its Institute of Hospitality in Siem Reap, Cambodia. Hotel de la Paix started this Shinta Mani hospitality school that doubles as a hotel. Selected students from needy neighbouring villages receive their training and graduation certificates. Its commitment and dedication to support the less fortunate community in Cambodia has changed many lives, supported many educations and brought a better future for Cambodia and its people. Shinta Mani's Institute of Hospitality is an award-winning programme targeted at young Cambodian adults coming from areas of risk. Since its inception in June 2004, it has changed the lives of over 100 individuals and their families, giving them a life full of purpose and hope of a better future. (shintamani.com)

At Shinta Mani hotel lunch was served by the hospitality students. There was some time for both groups of students to meet each other after this. These encounters lead to much astonishment as well as enchantment among students. Mr. Solomon Deleon, director of CBA (community based activities) explained their mission and results. Shinta Mani supported community based projects in villages around Siem Reap were visited in the afternoon, on site explanation was given by Mr. Solomon and his team.

\section{Day 5}

No organised program was offered during the morning, so students were free to discover people en places on their own. In Afternoon: a series of classroom sessions were planned for exchanging student experiences. There was room to discuss both the choices made in students' free time as well as the company visits in organised for them in smaller groups.

Figure 1. The 5-day program in Siem Reap. 
Table 1

Interviewees Field Research 2007-2009

Stephan Arrii, General Manager Knai Bang Chatt, Kep

Nick Butler, Coordinator Sam Veasna Center for Wildlife Conservation, Siem Reap

Martin Dishman, Managing Director The One Hotel, Siem Reap

Nick Downing, General Manager Hotel de la Paix Angkor, Siem Reap

Arjen de Haan, President Director Asialink Holidays, Bali

Noelene Henderson, Director of Sales and Marketing Hotel de la Paix Angkor, Siem Reap

Benoit Jancloes, General Manager FCC Angkor, Siem Reap

Sivanna Khoeung, Sales Director Artisans Angkor Cambodian Fine Arts \& Crafts, Siem Reap

Kate Lloyd-Williams, Program Manager Tourism International Finance Corporation (IFC) World Bank Group, Ho Chi Minh City

Raymond Pereira, General Manager Angkor Century Resort \& Spa, Siem Reap

Samnang Pok, Khmer Angkor Tour Guide Association, Siem Reap

Don Protasio, Curator Arts Lounge Hotel de la Paix Angkor, Siem Reap

Willem van de Put, Algemeen Directeur HealthNet TPO, Amsterdam

Ampor Samoeun, Director Sala Bai Hotel school, Siem Reap

Charley Todd, director of Cambodian Living Arts

Chitra Vincent, General Manager Shinta Mani Hotel and Institute of Hospitality, Siem Reap

Siem Reap and Angkor Wat are now fully integrated into the international tourism industry, with tour operators, airlines, capital and investment companies, and hotel chains dominating the area of Siem Reap and its airport (NHTV/ITMC student reports from 2009; Winter, 2007b). The Siem Reap 2- to-3 day attraction tourism product has been taken up into the world wide interrelated tourism business. Many services that tourists ask for are readily available including family businesses, restaurants, and souvenir markets. Expecting that tourists might seek more than the prime Angkor complex tourist attraction, even initiatives like Stay-another Day try to prolong and enrich visitor stays, experiences and spending (interview with K. Lloyd-Williams in 2008; NHTV/ITMC field student reports from 2008 and 2009).

Shortly after the take off of the tourism boom that took place in the Siem Reap area, the Authority for the Protection and Safeguarding of the Angkor Region (APSARA), the entity that manages the entire $100 \mathrm{~km}^{2}$ area of Angkor Wat, decided to shift its main focus from preservation to exploitation of the temple areas for benefit of the whole Cambodian economy (Winter, 2007b).

\section{Cambodian Perspectives: Modernization and Tourism Beyond Angkor Wat}

Angkor Wat is a primary attraction in Cambodia. Tourists, however, equally seek encounters with the context in which the temples are embedded: for example, tasting local food, experiencing the tropics, and authentically perceived situations. These are considered valuable add-ons to the primary attractions (Ashworth \& Tunbridge, 2005; Isaac, 2008). Next to the Angkor complex, Cambodia and Siem Reap have a unique and authentic heritage of modern buildings of internationally high standard. These were built after independence in 1953 (Grant Ross \& Collins, 2006) when Khmer elites started to build showing their Khmer pride with an own distinctive Khmer modern architecture stimulated by Le Corbusier inspired national architect Vann Molivann (Grant Ross \& Collins, 2006; Winter, 2007b). This has been hardly recognized by the direct tourism focused popular magazines and research.

New forms of art and architecture were developed and fostered from 1953 until 1970 that expressed a recognizable distinctive Khmer cultural style (Reyum Institute of Arts and Culture, 2001). A policy of stimulation of Khmer modern architecture resulted in a yet hardly discovered Khmer modern style of hotels, conference and exhibition centers, market buildings, and the like. Many survived the Pol Pot holocaust period when all developments came to a standstill. Many buildings have been restored already such as the Raffles Hotel Le Royal in Phnom Penh, others waiting for "inspired" money. The Cambodian modern style not only inspired to restore abandoned buildings like the Knai Bang Chatt Resort in coastal Kep (interview with S. Arrii in 2009) but also inspired investors to construct hotels in classic 1960s structures like the Amansara and the FCC Angkor in Siem Reap. The Art Déco style Hôtel de la Paix in the center of Siem Reap is a contemporary addition in line with the New Khmer Architecture with buildings that blended modern techniques with Cambodian tradition. The De la Paix, linked with Shinta Mani, is one of the important motivating players in the 
Khmer education initiatives in Siem Reap (interviews with D. Protasio in 2009 and C. Vincent in 2008 and 2009).

After a standstill of literally everything during the Khmer Rouge (1975-1979) and the consecutive Vietnamese influenced period (1980-1989) the local elites became active again. These elites started to invest in tourism businesses and became players in the SE Asian regional tourism markets. Khmer businessmen who returned out of their "diasporas," on the same track as the many NGOs that flocked Cambodia, started to invest not only in business but also in education of the educationally deprived Khmer. Field research in 2008 and 2009 revealed, for example, the closely related Hotel de la Paix and the Shinta Mani Hotel/hotel-school as typical examples of such relations between education and commerce. Socially inspired developments such as community-based development projects go hand in hand with the entrepreneurial need for a trained labor force for the tourist industry in which Khmer capital is taking stakes.

Modernization is manifested in many more aspects of the lives of those who live and work in destinations, and this features in a contextual approach. Another aspect that is featured as a result of adopting a contextual approach is the Cambodian perspective on life. This specific perspective influences daily life activities, behavior at home and in business, but these are not very visible on the surface.

Up until the end of the French colonial time Cambodia was a relatively stable rural society with a mainly locally focussed economy. Kiernan (1996 as cited in van de Put, 2002) stated that "Pre-Revolutionary" Cambodia was $80 \%$ peasant, $80 \%$ Khmer, and $80 \%$ Buddhist. First, it was an overwhelmingly rural economy. Its village society was decentralized, its economy unintegrated, dominated by subsistence rice cultivation. Compared to Vietnam, its villagers participated much less in village-organized activities. They were often described as individualistic; the nuclear family was the social core.

Accompanying the economic development after independence Cambodia became acquainted with the concept of an international economy. As a result of worldwide and world-size politics and military interventions, Cambodia was sucked into the American War in Vietnam, which spread across
Cambodia. Political unrest grew and resulted finally in civil wars and revolutionary situations, the Khmer Rouge period, and the Vietnamese Occupation. This all pressed the Khmer people and society into traumatic life times that still smolder close under the surface in every day existence of the Cambodians (lecture by Van de Put in 2007). When Cambodia became independent again in 1990 the world fabricated an explanation of what had happened, and this "Standard Total View" (Vickery, 1984) reduced the complex Cambodian reality to a story of a harmonious, innocent, self-supporting society, made up of smiling people, that was suddenly disrupted by the terror of a group of barbarous communists. It allowed all those for whom it was politically convenient to see the rule of the Khmer Rouge as a breach in timeless Khmer history. The context of a long existence of cruelty in Khmer history and the more recent effect of the massive bombing campaign of the US in 19721973 escaped attention.

Cambodian history is complex and tragic. The period of the Khmer Rouge (1975-1979) saw evacuation of cities, execution and starvation, and closure of international borders. In order to understand the Cambodian perspective on life one has to understand the country, the culture, and its people at various levels. Political explanations of the past strengthened the tendency of individual people to refer to "standard histories." This safe representation of what had happened to Cambodia as a whole served to avoid political risk, while there was little interest among families in details of what had happened to others. "Local histories" (Van de Put \& Eisenbruch, 2002) play a role till today: Some people considered the civil war and the massive bombarding a more difficult period than the Khmer Rouge years. Others suffered more after the fall of Pol Pot, when they were caught between warring factions at the Thai border. It is difficult to understand the coping mechanisms of all those that still function-how do people cope with loss, and what do they believe to be causes of illness and misfortune? When people talk about hope, desperation, suicide, guilt, anger, and acceptance, one needs to know what is meant.

Next to those who survived and cope with the past, new generations born after the disastrous times form the majority of Cambodians. This gen- 
eration grows up with a fresh, yet heavily burdened, perspective on their future with opportunities offered by tourists who mainly focus not on their recent achievements, nor the troubled times three decades ago, but on the centuries old history of Khmer Angkor.

Coming to a full understanding of Cambodian tradition and culture is not the objective of the student's research project in Cambodia. The main aim of this research article, therefore, is to shed light on an unexamined but critical aspect of this contextual approach, its impacts, arguing that one cannot "fully" understand Cambodian tourism without trying to integrate and understand Cambodian history, culture, and economy. Although Cambodia itself is still a homogeneous society (Van de Put \& Eisenbruch, 2002), because tourism has developed rapidly in Siem Reap within the context of a multiplural economy, it is expected that Cambodian society will change and modernize alike.

\section{Discussion and Conclusion}

Contextual education in Cambodia means implementing a research approach whereby there is no standard or predetermined set of variables based on the models of tourism development. Nothing is left out beforehand in this more explorative research approach, aiming at openness for those implicit, hidden perspectives and variables that may play a leading role in orientations and implementations of development. The need for more space for Asian and Cambodian perspectives very soon becomes apparent. This seems self-evident in a pluralist discourse, but as we have argued, dominant tourism development discourse seems to remain somewhat stuck in core-periphery dynamics and in "AngloWestern" centrism. This situation has far reaching implications: Western students tend to see mainly Western tourists and connect with Western managers or stakeholders on the destination, hearing in turn Western perspectives on Cambodia. In addition to this bias, there is the more persistent and longer-term orientalism (Said, 2003) as a phenomenon keeping in place the distance with the other, and thus with the Cambodian and other very relevant Asian perspectives.

The extensive 5-day program we designed in Siem Reap for mainly Western students attempt- ed to create a greater space for local (Cambodian) and regional Asian knowledge and perspectives. Instead of arranging standard surveying and interviewing sessions we arranged opportunities to discuss, to meet and discover the underlying aspects of reality. The space created lead to room for personal stories and "local histories" ever present in the background of any destination to emerge, and that is what we want students to hear and look for.

Besides meeting the guides while performing their profession, showing the Angkor complex, students could ask guides to show their village, their daily life situation, and talk about it as well as about their ideas about the tourists and their attractions.

In meeting students at the Shinta Mani and Sala Bai hotel schools our NHTV students heard about the Cambodian students' backgrounds, their personal motivation, and how they are experiencing the sudden and enormous rise of tourism in their province and the need for educated and trained people for this industry. The perceived once in a lifetime opportunity for the Cambodians gives an extra dimension for interpretation of Siem Reap's tourism development.

The aim of this article was to explore and discuss contextual education as a best practice for knowledge production in the field of tourism. Student experiences and observations provide important input in the discussion on knowledge production in tourism, as well as the added value of this contextual approach in this knowledge production process.

\section{Student Experiences}

The 5-day program culminated on the last day when students were convened to share impressions and insights gained. A rich and dynamic event took place then, where there was room for the "hidden dimensions" including cultural dynamics of the destination Siem Reap and Angkor Wat. These dimensions could be felt as students sought to encounter the places and the people in an unstructured way. After a few "warming up" questions about how they bargained for their accommodations, what pictures they took, what messages they sent home, the discussion was slowly geared towards their "meaningful" experiences. The following quotes reflect some of them ranging from awe and admiration: 
Yesterday we visited a village, local people, to see that people had almost nothing, children with dirty clothes, it was impressive, that people live like that. For me it was the village too, they picked up flowers and gave them to us, they have nothing and then they give something to us.

We had conversations with our tuk tuk driver about his family life; we talked about life, healthcare, school system. There was an interest from both sides to compare. People are open; they like to share and are curious about students and tourists as well.

We arrived with a few real images in our minds and returned with thousands.

Talking to hospitality students from Sala Bai, at first it was difficult, then it became more fun, they wanted to know where we live.

\section{To tensions and disturbances:}

Shocking for us was that guides could talk so openly about the history and the fact that people died, his whole family, and how he survived... but also that he seemed to have told it many times.

I felt I was spending much money, but perhaps not to the right children.

For a moment I was ready to ask him further questions ... but as soon as I opened my mouth I decided this was not an appropriate time to start a discussion.

They left us often wondering what they might think of us and made us somehow feel a bit stupid. But we never felt unwelcome. . . .

We often felt quite strange and somehow ashamed, wandering through the local village, seeing the poverty and taking pictures of everything.

These sessions revealed the tension between the open assignment calling upon broad-minded discoveries about people and places on the one hand, and the existence in students' minds of theoretical and cultural preconceptions on the other. The added value hereof is a growing consciousness of future professionals of their preconceptions, stereotypes, and assumptions potentially standing in the way of deeper understanding. Some students felt a culture shock, others not.
Dutch student: I felt in culture shock. At the airport, looking out of the bus. What I saw from the bus. A dentist operating in the dust, in the open, with a small sign by the shack.

Indian student: I see the same way of living like in my own country. Poverty, I understand why they do things, trying to earn money, like the tuk tuk driver, bargaining. ...

A substantial part of students' reflections on their stay were self-reflections, contrasting their worldviews and assumptions with the others, as well as about their learning.

Topics that were talked about openly were topics like relatives, jobs, and everyday life. Our blind spots were often to judge things according to our own perspectives, and to try to rationalize situations through our Western eyes.

Meeting Srey Keung was a very pleasant cross cultural experience, because we instantly liked each other.... It was a wonderful event during which both sides learned something about the other's culture, which was new, strange, but really fascinating.

\section{What the Contextual Approach Reveals}

Field research findings could be divided into insights gained in "internal dynamics" of Cambodian society and "external forces," referring to the regional and international political and economic position of Cambodia which have been and are still shaping developments and society. This distinction has the advantage of providing room for the Cambodian perspective to emerge, which tends - as we have argued - to be reduced or silenced by the louder "global" and regional voices. For a more general discussion on contextual education as best practice for knowledge production in the field of tourism also see Portegies et al. (2009).

Student observations combined with our own provided confusing, emotional, and dynamic snapshots of Cambodian life in and around Siem Reap. Some local informants added further insights: Mr. Pok Samnang, head of the Khmer Tour Guide Association, also the guides accompanying our students in small groups for a full day; the tuk tuk drivers the students befriended. There were also many informal conversations held with people living in Siem Reap around the organized part of the program. 
Observations of life in and around the Pagoda, discussions with fellow Cambodian students and with reception staff, tuk tuk drivers, and tour guides lead to a careful conclusion to be further explored that there are powerful dynamics at play in Cambodian society to survive and live, with an outward look. Hotel staff but also youngsters hanging around shops and market stalls were learning languages during and after work time. People express interest, show curiosity in the lives of their visitors. Many people, of different age categories, came across as self-confident, going after opportunities, however small, but doing business. This power struck us not just in formal or typical tourist situation, but also in the backyards, behind market stalls, by tuk tuk waiting areas. The use and expression of humor were indicative. In addition to these tourism related observations, it was also astonishing to learn about the way society has dealt with external influences in several ways. In architecture this has lead for example to constructions and landscapes of interest showing modern Khmer struggles and vitality.

These findings are of a very different nature than those resulting from, for example, the still widely used impact studies approach. The application of impact studies results, as has been discussed by Meethan (2001) and Portegies et al. (2009), results in a rather sterile listing of positive impacts on the one hand and negative impacts on the other. The approach used here, "letting the situation speak for itself," led to the insight that tourism is seen as an opportunity, and that many local people benefit from it economically and socially. There is an open attitude to the future - $\mathrm{a}$ desire to learn languages and to make lives better. Many student testimonies converged to this, like for example:

Our tour guide Pen explained to us that the Cambodians are very proud of the temples, because it also reminds them on the achievement of their ancestors.... However it is more than that, it is also a source of income as so many tourists come to visit it.

Wog [17 years old, motorbike taxi-driver, son of a fisherman] spoke very open and honest. He talked about dreams, but always came back to reality. $\mathrm{He}$ told me that to realize his dreams he needs more money to pay for hotel training and an additional English class.
And after this student hesitantly asked Wog why he was not saving his earned money and moving to Siem Reap to fulfill his dream,

Wog smiled and very slowly replied: I want to support my family and stay with my family. I do not have my own money and I will be with the fish in the village. I paused for a second and waited in which direction the conversation continues.... When I asked Wog if he traveled, he told me that he likes Siem Reap and that his wish is to meet many rich tourists from all over the world in Siem Reap. In the future Wog will stay with his family, the fish, and the motorbike.

One senses the student's slow approach and the open-endedness of the conversation. There are more questions to be asked and the picture is not yet clear. But the situation is speaking. Also, students' detected pride in their encounters, as the following quote equally shows:

We also noticed that all Cambodians were quite proud of their country and of Angkor Wat in particular. When we showed an interest in their country, their way of life, they were happy to talk to us and conveyed us the feeling of being very proud of their country.

We also identified socially inspired developments, initiated both through private initiatives (Shinta Mani, Hotel de la Paix, Paul Dubrule Hotel School) as well as through public and international projects (Sala Bai Hotel School, Sam Veasna, Cambodian Living Arts). These developments are of direct interest for tourism development. People working and setting up businesses seem to have a very special "connection" to the destination.

Our fieldwork made apparent that there seems to be a coexistence of several (tourism) destinations in this location. Different aspects, lengths of stay, different local players, hotels, restaurants, guides, for different kinds of - mainly Asian - tourists. Their meanings attributed to Siem Reap and Angkor Wat vary substantially and so do their respective experiences of the destination. Recognizing the diversity of tourism markets, also the diversity within Asian markets, students showed growing awareness of the world beyond Europe and the need to question some of their worldviews. Taken a few steps further, this could lead to new perspectives on a destination like 
Cambodia or Siem Reap, and to a generation of new ideas and opportunities for development.

Finally and perhaps a disturbing line of thought emanating from the fieldwork is the question of whether Angkor Wat is Cambodia's main attraction. The tourist gaze (Urry, 2002) and other powerful tourism discourses (Mowforth \& Munt, 2008) contribute to our (Western) conviction that it is. But numerous student encounters expressed in personal diaries, logbooks, and later articles, show that the highlights of their experiences in Cambodia lie elsewhere. The contextual approach sensitized the students to the different societies and networks present in Siem Reap. This knowledge goes further and deeper than mere tourism or tourism-related knowledge. This knowledge contributes to a process of "de-exotization" of the destination and more interest for the cultural dynamics, both similar and different, both local and global. This aspect could be further explored and is undoubtedly meaningful Cambodia's future opportunities for development.

\section{Acknowledgments}

The authors wish to express their gratitude for the generosity the interviewees showed in sharing their knowledge, time, and experiences, and for contributing to an unforgettable experience for hundreds of young international students in Cambodia. Equally are we grateful to the ITMC students with whom we traveled to Cambodia in 2008 and 2009 and who shared their experiences and astonishment with us.

\section{References}

Alneng, V. (2002). The modern does not cater for natives: Travel ethnography and the conventions of form. Tourist Studies, 2(2), 119-142.

Appadurai, A. (1996). Modernity at large: Cultural dimensions of globalisations. Minneapolis, MN: University of Minnesota Press.

Ashworth, G. J., \& Tunbridge, J. E. (2005). Moving from blue to grey tourism: Reinventing Malta. Tourism Recreation Research, 30(1), 45-54.

Beech, H. (2005, May 30). Deals and diplomacy, China's influence in Southeast Asia is growing as its trade and investments boom. Time Asia, 14-20.

Castells, M. (2000). The information age: Economy, society, and culture (Vol. I, II, and III). Oxford: Blackwell Publishers.

Edensor, T. (1998). Tourist at the Taj: Performance and meaning at a symbolic site. London: Routeldge.
Grant Ross, H., \& Collins, D. L. (2006). Building Cambodia: "New Khmer architecture" 1953-1970. Bangkok: The Key Publisher Company Ltd.

Hall, C. M. (2005). Tourism: Rethinking the social science of mobility. Harlow: Pearson Education.

Hannerz, U. (1993). Cultural complexity: Studies in the social organisation of meaning. New York: Columbia University Press.

Isaac, R. K. (2008). Understanding the behaviour of cultural tourists: Towards an understanding of Dutch cultural tourists. Ph.D. dissertation, Breda, NHTV Academic Expertise Series 5.

Isaac, R. K., Platenkamp, V., \& Portegies, A. (2009). Introduction. In: R. K. Isaac, V. Platenkamp, \& A. Portegies (Eds.), Voices in tourism development: Creating spaces for tacit knowledge and innovation. Breda: NHTV Expertise Series 8 .

Lengkeek, J., \& Platenkamp V. (2004). The international classroom of tourism studies. Paper presented at the International Conference for Sociologists, Lesobs, Greece.

Lennon, J. (2009). Tragedy and heritage: The case of Cambodia. Tourism Recreation Research, 34(1), 35-43.

Meethan, K. (2001). Tourism in global society: Place, culture, consumption. New York: Palgrave.

Ministry of Tourism. (2000). Cambodia tourism statistical report 2000. Phnom Penh: Author.

Ministry of Tourism. (2003). Cambodia tourism statistical report 2003. Phnom Penh: Author.

Ministry of Tourism. (2008). Cambodia tourism statistical report 2008. Phnom Penh: Author.

Ministry of Tourism. (2009). Cambodia tourism statistical report 2009. Phnom Penh: Author.

Mowforth, M., \& Munt, I. (2008). Tourism and sustainability: Development, globalisation, and new tourism in the Third World. London: Routledge.

Murshid, K. A. S., \& Ballard, B. M. (Eds.). (2005). Cambodia annual development review. Phnom Penh: Cambodia Development Resource Institute.

Phuong, K. (2003). Tourism sites in Cambodia. Phnom Penh: Pnleu Khmer Printing and Publishing House.

Platenkamp, V. C. J. M. (2006). Contexts in tourism and leisure studies, a cross-cultural contribution to the production of knowledge. Ph.D. dissertation, Breda, NHTV Academic Studies 5.

Portegies, A., de Haan, T. Z., \& Platenkamp, V. (2009). Knowledge production in tourism: Contextual learning processes in destination studies. Tourism Analysis, 14(4), 523-536.

Reyum Institute of Arts and Culture. (2001). Cultures of independence: An introduction to Cambodian Arts and Culture in the 1950s and 1960s. Phnom Penh: Reyum Institute.

Saïd, E. (2003). Orientalism. London: Penguin Books.

Urry, J. (2002). The tourist gaze. London: Sage.

Van de Put, W. A. C. M., \& Eisenbruch, I. M. (2002) The Cambodian experience. In J. de Jong (Ed.) Trauma, war, and violence: Public mental health in sociocultural context. New York: Plenum Kluwer. 
Vickery, M. (1984). Cambodia 1975-1982. Boston: South End Press.

Williams, A. M., Hall, C. M., \& Lew, A. (2004). Conclusions: Contemporary themes and challenges in tourism. In A. Lew, C. M. Hall, \& A. M. Williams (Eds.), Companion to tourism. Oxford: Blackwell.

Winter, T. (2007a). Rethinking tourism in Asia. Annals of Tourism Research, 34(1), 27-44.

Winter, T. (2007b). Post-conflict heritage, postcolonial tourism, culture, politics and development at Angkor. New York and Oxon: Routledge

Winter, T. (2009). Asian tourism and the retreat of AngloWestern centrism in tourism theory. Current Issues in Tourism, 12(1), 21-31.

Winter, T., Teo, P., \& Chang, T. C. (Eds.). (2009). Asia on tour. London: Routledge.

World Travel and Tourism Council. (2008). The travel and tourism economic research. London: Author. 